\title{
SOSIALISASI KEBERSIHAN LINGKUNGAN DAN PEMBUATAN TEMPAT SAMPAH DARI BAN BEKAS
}

\author{
Luh Gede Sumahiradewi'1), Baiq Pitria Ningsih"2), Edwin Saputra ${ }^{2}$, Rahmat Sudiar2), \\ I Gede Wira Kusuma Artha'), M. Rauhul Hidayat ${ }^{3)}$, Musa Eka Yudi Septian ${ }^{3)}$, Ahmad Fatoni'), \\ Rizal Hamami ${ }^{3)}$, Hasdianto ${ }^{3)}$, Ahmad Rizal ${ }^{3)}$, Agus Salim ${ }^{3)}$, Ega Sukma Firdaus ${ }^{4)}$. \\ 1)Program Studi Budidaya Perairan, Fakultas Perikanan, Universitas 45 Mataram, Mataram, NTB, Indonesia \\ 2)Program Studi IImu Hukum, Fakultas Hukum, Universitas 45 Mataram, Mataram, NTB, Indonesia \\ 3)Program Studi Ilmu Agroteknologi, Fakultas Pertanian, Universitas 45 Mataram, Mataram, NTB, Indonesia \\ 4)Program Studi IImu Komunikasi, Fakultas IImu Sosial dan IImu Politik, Universitas 45 Mataram, Mataram, NTB, \\ Indonesia
}

Corresponding author : Luh Gede Sumahiradewi

E-mail : luhdechem@gmail.com

Diterima 12 Oktober 2021, Direvisi 18 Oktober 2021, Disetujui 18 Oktober 2021

\begin{abstract}
ABSTRAK
Menumbuhkan kesadaran masyarakat untuk hidup bersih dan bebas dari sampah merupakan cita -cita kita bersama, tidak hanya masyarakat yang berada di daerah perkotaan tetapi juga masyarakat yang ada di pedesaan. Kurangnya pengetahuan dan kesadaran masyarakat Desa Jeringo akan pentignya menjaga lingkungan, dan bagaimana cara mengelola sampah, dapat dilihat dari masih banyaknya warga Desa Jeringo yang membuang sampah di kebun bahkan disungai, serta kurangnya tempat pembuangan sampah di rumah - rumah ataupun ditempat umum. Untuk menumbuhkan kesadaran masyarakat tentang peduli lingkungan, membutuhkan edukasi yang harus dilakukan secara terus menerus, agar dapat merubah kebiasaan dan pola pikir masyarakat. Pengabdian ini bertujuan menumbuhkan kesadaran masyarakat untuk membuang sampah pada tempatnya serta mensosialisasikan cara pembuatan tempat sampah dari ban bekas. Bentuk kegiatan berupa sosialisasi mengenai kebersihan lingkungan dan mengadakan pelatihan kepada masyarakat untuk membuat tempat sampah dari barang - barang yang ada disekeliling kita yang sudah tidak terpakai salah satunya menggunakan ban bekas. Hasil dari kegiatan adalah bertambahnya pengetahuan masyarakat terhadap pentingnya menjaga kebersihan lingkungan melalui pemanfaatan tempat sampah yang telah dibuat dilihat dari lingkungan tempat tinggal yang sudah bebas dari sampah, serta kemampuan masyarakat dalam membuat sendiri tempat sampah dari ban bekas.
\end{abstract}

Kata kunci: kebersihan lingkungan; sampah; tempat sampah; ban bekas

\begin{abstract}
Raising public awareness to live clean and free from waste is our common goal, not only for people in urban areas but also for people in rural areas. The lack of knowledge and awareness of the people of Jeringo Village about the importance of protecting the environment, and how to manage waste, can be seen from many resident of Jeringo Village who litter in the garden and even in the rivers, and also the lack of landfills in homes or in public places. To raise people awareness about the environment, needs education that must be carried out continuously, in order to change people's habits and mindsets. This service aims are to raise public awareness to dispose waste in its place and to socialize how to make trash cans from used tires. The activity that will be carried out is socializing about environmental hygiene and holding training for the community to make trash bins from items around us that are no longer used, one of them use tires. The result of the activity is increasing public knowledge about the importance of keeping the environment clean through the use of trash cans that have been made seen from the living environment that is free from waste, as well as the ability of the community to make their own trash cans from used tires.
\end{abstract}

Keywords: environmental cleanliness; waste; trash can; used tires

\section{PENDAHULUAN}

Berdasarkan UU No. 18 Tahun 2008

tentang Pengelolaan Sampah, sampah didefinisikan sebagai sisa kegiatan sehari-hari manusia atau proses alam yang berbentuk padat atau semi padat berupa zat organik atau zat anorganik bersifat dapat terurai atau tidak dapat terurai yang dianggap sudah tidak berguna dan dibuang ke lingkungan. Sampah yang dibuang ke lingkungan dapat berupa 
sampah organik (sisa-sisa rumah tangga seperti daun, sisa makanan, kulit buah), sampah anorganik (plastik, kaleng, besi, styrofoam, dIl) serta sampah B3 (Bahan Berbahaya dan Beracun seperti batu baterai, bohlam, kemasan pestisida, dll). Semakin meningkatnya pertumbuhan penduduk, maka semakin meningkat pula jumlah sampah yang dihasilkan, tidak hanya itu, keanekaragaman jenis dari karakteristik sampah juga meningkat, sehingga pengelolaan sampah menjadi masalah nyata yang perlu diperhatikan (Mahyudin, 2017)

Masalah sampah saat ini tidak hanya menjadi permasalahan di kota-kota besar saja, melainkan juga di desa-desa. Kebiasaan membuang sampah sembarangan dilakukan hampir di semua kalangan masyarakat, tidak hanya warga miskin, bahkan mereka yang berpendidikan tinggi juga melakukannya. Hal ini sangat menyedihkan karena minimnya pengetahuan tentang sampah dan dampaknya. Perilaku buruk ini semakin menjadi karena minimnya sarana kebersihan yang mudah dijangkau oleh masyarakat di tempat umum (Mulasari \& Sulistyawati, 2014).

Dewasa ini pengelolaan sampah masih menjadi tantangan karena masih diperlukan adanya peningkatan kesadaran masyarakat untuk berpartisipasi secara aktif dalam mengolah sampah (Yunik'ati et al., 2019). Peningkatan pencemaran lingkungan diakibatkan karena kurang memadainya tempat dan lokasi pembuangan sampah, kurangnya pemahaman masyarakat dalam pemanfaatan sampah serta keengganan masyarakat dalam memanfaatkannya. Berdasarkan beberapa hal di atas yang dapat memperburuk kondisi lingkungan, peran aktif masyarakat didukung dengan fasilitas tempat sampah dan pengolahan sampah menjadi kunci untuk terwujudnya lingkungan masyarakat yang sehat (Nilam Sari, 2017)

Penggunaan tempat sampah merupakan salah satu upaya penanggulangan sampah dari sumbernya. Tempat sampah memberikan kesan daya tarik sendiri agar tidak membuang sampah sembarangan (Fitri et al., 2019).

Menurut (Farkhan et al., 2019) dengan pengadaan bak sampah meningkatkan kesadaran masyarakat desa untuk tidak membuang sampah sembarangan.

Tempat sampah sendiri bisa dibuat dari berbagai bahan, mulai dari barang - barang bekas, atau bahan - bahan lain yang ada dilingkungan sekitar seperti bambu dan lain lain. Hal tersebut sesuai dengan pendapat (Sari \& Umama, 2019) dimana dengan adanya pelatihan pembuatan tempat sampah mampu meningkatkan pengetahuan masyarakat bahwa tempat sampah tidak harus selalu dibeli, tetapi dapat dibuat sendiri dengan memanfaatkan bahan-bahan yang tersedia di sekitar.

Pada kegiatan pengabdian masyarakat yang dilaksanakan, ban bekas yang digunakan diperoleh dari kepala desa jeringo yang memiliki banyak ban bekas yang sudah tidak digunakan. Ban bekas tersebut akan dibentuk menjadi tempat sampah yang unik dan menarik dengan tujuan agar masyarakat gemar membuang sampah pada tempatnya. Serta menjadi media pembelajaran bagi masyarakat agar dapat mengelola ban bekas menjadi sesuatu yang bermanfaat bagi lingkungan.

\section{METODE}

Pelaksanaan program kegiatan pengabdian masyarakat ini dilaksanakan di Desa Jeringo Kecamatan Gunungsari Kabupaten Lombok Barat, selama 1 (satu) bulan dimulai dari tanggal 1 Agustus 2021 sampai dengan 31 Agustus 2021. Mitra dalam kegiatan ini berasal dari aparatur desa (kadus, RT, RW), ibu-ibu PKK serta remaja karang taruna Desa Jeringo, dengan total peserta berjumlah 20 orang.

Metode yang digunakan yaitu wawancara secara langsung dengan warga masyarakat Desa Jeringo. Adapun kegiatan terbagi dalam 3 tahap pelaksanaan seperti pada Gambar 1.

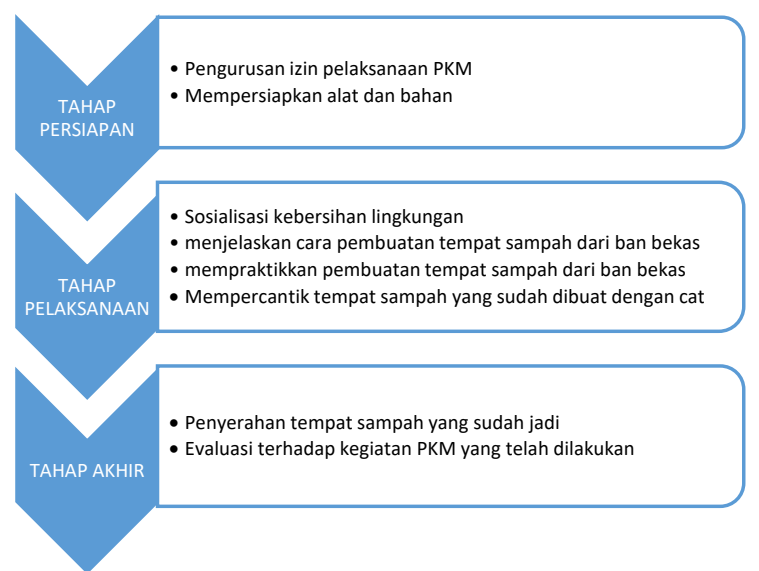

Gambar 1. Bagan metode pelaksanaan

$$
\text { kegiatan }
$$

\section{HASIL DAN PEMBAHASAN}

\section{Tahap persiapan}

Pelaksanaan program diawali dengan pertemuan panitia dengan kepala desa Jeringo bertempat di aula kantor Desa Jeringo guna mengurus izin untuk melakukan kegiatan. Dimana kegiatan selanjutnya melakukan koordinasi dengan RT dan Kadus setempat.

\section{Tahap Pelaksanaan}

Kegiatan sosialisasi kebersihan lingkungan kepada masyarakat Desa Jeringo 
dilaksanakan di Taman Telaga Sikur Desa Jeringo, adapun materi yang disampaikan meliputi dampak mengabaikan kebersihan lingkungan, upaya dalam menjaga kebersihan lingkungan dan manfaat dalam menjaga kebersihan lingkungan, serta memberi pengetahuan kepada masyarakat bahwa tempat sampah dapat dibuat sendiri dengan memanfaatkan bahan-bahan yang ada di alam sekitar kita, artinya tidak perlu mengeluarkan biaya untuk memiliki tempat sampah.

Kegiatan Sosialisasi ini diharapkan masyarakat menjadi lebih sadar lagi terhadap kebersihan di lingungan tempat tinggal mereka.

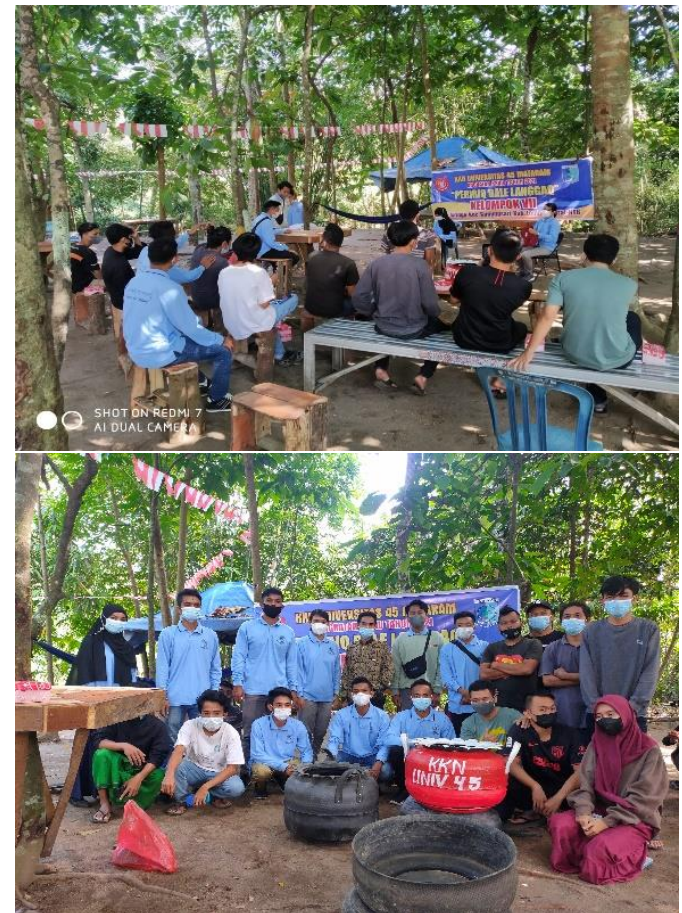

Gambar 2. Sosialisasi Kebersihan Lingkungan

(Sumber : Dokumen Pribadi).

Kegiatan dilanjutkan dengan menjelaskan sekaligus mempraktikkan cara pembuatan tempat sampah dari ban bekas. Kegiatan pembuatan tempat sampah dari ban bekas ini diikuti oleh seluruh peserta dengan sangat antusias. Seluruh peserta ikut berpartisipati aktif dalam membuat tempat sampah dari ban bekas ini.

Adapun tahapan pembuatan tempat sampah sebagai berikut :

1. Mepersiapkan alat dan bahan yang akan digunakan. Bahan berupa ban bekas, bisa menggunakan ban mobil, ban truk atau ban dengan ukuran sedang. Sedangkan alat-alat yang disiapkan yaitu cutter, gunting, paku, palu dan aneka warna cat.

2. Memotong atau mengiris bagian tepi luar ban secara melingkar menggunakan cutter, irisan tidak boleh terlalu tebal atau tipis, selanjutnya membalik ban, bagian potongan berada di dalam sedangkan bagian dalam ban berada di luar. Tahap ini merupakan bagian paling sulit dalam proses pembuatan tempat sampah dari ban bekas. Kemudian tutup bagian bawah tempat sampah dengan potongan ban, dibentuk seperti anyaman agar air bisa keluar langsung

3. Tempat sampah yang sudah selesai dibentuk selanjutnya diberikan hiasan yang juga berasal dari potongan ban, kemudian dicat sesuai dengan kreatifitas masing-masing dan diberi identitas kegitan.

Adanya kegiatan ini diharapkan agar warga tidak hanya sekedar menggunakan tetapi juga diajarkan dalam proses pembuatannya sehingga nantinya dapat membuat secara mandiri, dan dapat menghasilkan dalam jumlah banyak sehingga kebutuhan akan tempat sampah di Desa Jeringo dapat terpenuhi.

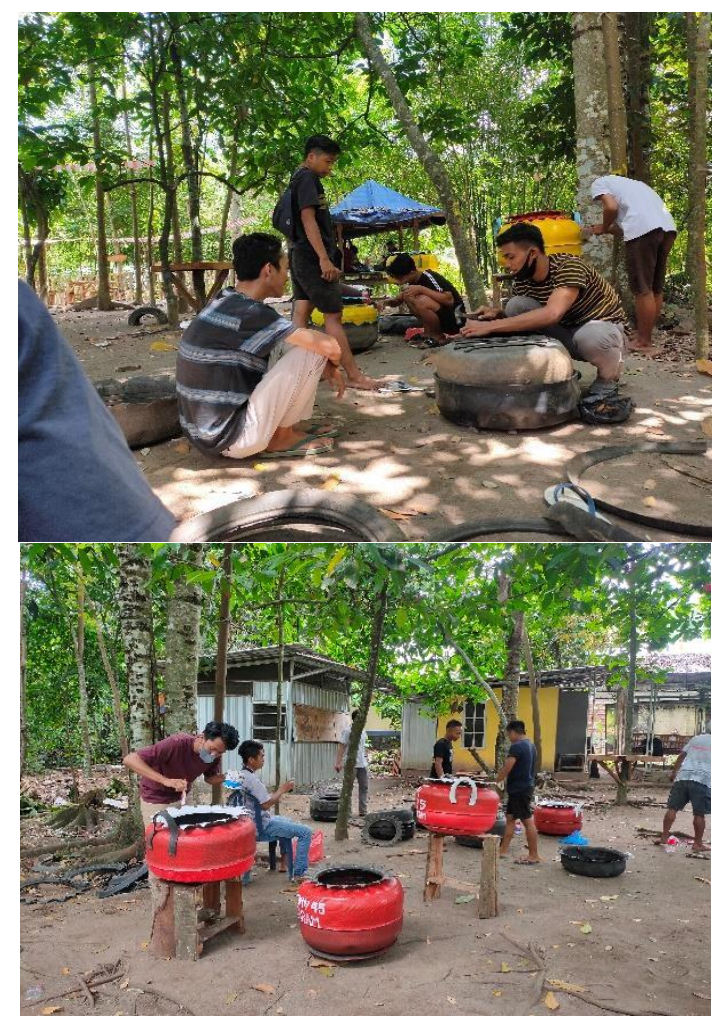

Gambar 3. Pelatihan Pembuatan Tempat sampah dari ban bekas (Sumber : Dokumen Pribadi) 


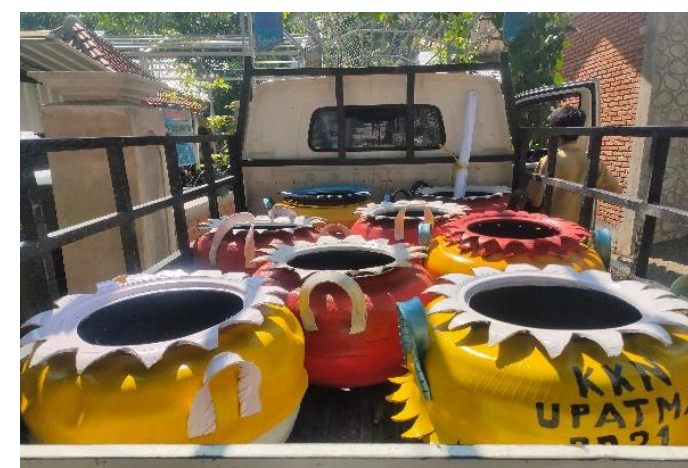

Gambar 4. Tempat sampah dari ban bekas (Sumber : Dokumen Pribadi)

\section{Tahap akhir}

Tempat sampah yang berhasil dibuat sebanyak 5 buah ditambah dengan yang telah dibuat sebelumnya oleh tim sehingga berjumlah 10 buah. Selanjutnya tempat sampah yang telah selesai dicat diletakkan pada tempat - tempat publik seperti di sekolah - sekolah, masjid, puskesdes, kantor desa, dll.

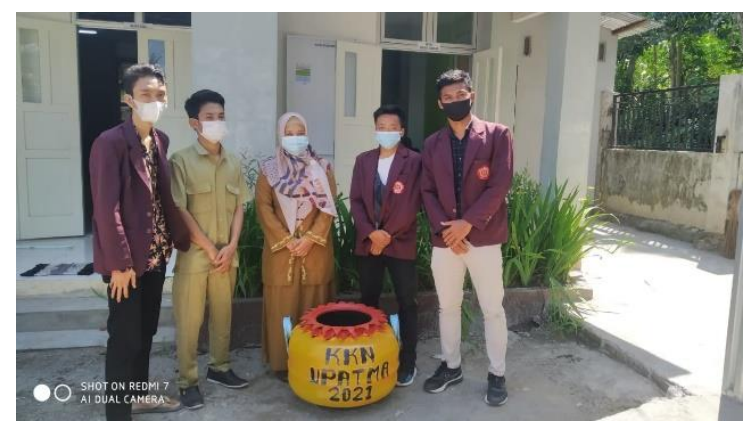

Gambar 5. Penempatan Tempat Sampah di PUSKESDES Desa Jeringo (Sumber : Dokumen Pribadi)

Tahap akhir dari kegiatan PKM ini adalah evaluasi terhadap program yang telah dilakukan. Evaluasi program dilakukan sebanyak dua kali dilakukan melaui interview dan pengamatan langsung di lapangan. Evaluasi pertama dilakukan setelah selesai pemberian materi dalam bentuk diskusi, hasilnya peserta kegiatan menjadi semakin terbuka pemahamannya akan pentingnya menjaga kebersihan lingkungan dan dengan pelatihan pembuatan bak sampah peserta menjadi memiliki pengetahuan baru dalam memanfaatkan ban bekas menjadi lebih berguna.

Evaluasi kedua dilakukan beberapa hari setelah kegiatan terlaksana. Berdasarkan evaluasi dapat dilihat 15 peserta dari 20 peserta sudah mulai menjaga kebersihan lingkungan dengan membuang sampah dapa tempatnya, selain itu terdapat beberapa peserta yang sudah membuat tempat sampah dari ban bekas untuk diletakkan di sekitar tempat tinggal mereka.

\section{SIMPULAN DAN SARAN}

Simpulan dari kegiatan pengabdian masyarakat ini adalah dengan kegiatan sosialisasi kebersihan lingkungan dan pembuatan tempat sampah dari ban bekas dapat merubah pola pikir masyarakat terhadap pentingnya menjaga kebersihan lingkungan serta sebagai motivasi bagi masyarakat Desa Jeringo khususnya untuk lebih meningkatkan kebersihan lingkungan dengan membuang sampah pada tempatnya.

Saran dari kegiatan pengabdian masyarakat ini adalah untuk kedepannya diharapkan masyarakat tetap memiliki kesadaran untuk perduli terhadap kebersihan lingkungan. Kebiasaan membuang sampah dipekarangan dan dibiarkan berserakan perlu dirubah dan perlu ada pemantauan lanjutan, di harapkan pihak Desa Jeringo secara berkelanjutan untuk memberikan himbauan agar masyarakat merubah kebiasaan membuang sampah sembarangan dan tetap menjaga lingkungan desa agar bersih dari sampah.

\section{UCAPAN TERIMAKASIH}

Ucapan terima kasih disampaikan kepada Lembaga Penelitian dan Pengabdian kepada Masyarakat (LPPM), Universitas 45 Mataram, yang telah memberikan kesempatan untuk dapat melakukan program pengabdian kepada masyarakat ini. Ucapan terima kasih juga disampaikan kepada warga dan segenap jajaran Pemerintah Desa Jeringo, Kecamatan Gunungsari, Kabupaten Lombok Barat yang telah telah menerima dengan sangat baik kegiatan pengabdian masyarakat yang dilaksanakan.

\section{DAFTAR RUJUKAN}

Farkhan, M., Zamroni, M., Ardiansyah, G., \& Hatta, M. (2019). PEMBUATAN BAK SAMPAH UNTUK PEDULI LINGKUNGAN DI DESA NGARESREJO KECAMATAN SUKODONO KABUPATEN SIDOARJO. Among: Jurnal Pengabdian Masyarakat, 1(1), 32-37.

Fitri, R., Siregar, H. F., \& PengalamanTarigan, A. S. (2019). Peduli Lingkungan bagi Anak Berkebutuhan Khusus (ABK) dengan Penerapan Tong Sampah Ceria. Prosiding Konferensi Nasional Pengabdian Kepada Masyarakat Dan Corporate Social Responsibility (PKMCSR), https://doi.org/10.37695/pkmcsr.v2i0.451

Mahyudin, R. P. (2017). KAJIAN PERMASALAHAN PENGELOLAAN SAMPAH DAN DAMPAK LINGKUNGAN DI TPA (TEMPAT PEMROSESAN 
AKHIR). Jukung (Jurnal Teknik Lingkungan), 3(1). https://doi.org/10.20527/jukung.v3i1.3201

Mulasari, S. A., \& Sulistyawati. (2014). KEBERADAAN TPS LEGAL DAN TPS ILEGAL DI KECAMATAN GODEAN KABUPATEN SLEMAN. KEMAS: Jurnal Kesehatan Masyarakat, 9(2), 122-130.

Nilam Sari, P. (2017). ANALISIS PENGELOLAAN SAMPAH PADAT DI KECAMATAN BANUHAMPU KABUPATEN AGAM. Jurnal Kesehatan Masyarakat Andalas, 10(2). https://doi.org/10.24893/jkma.v10i2.201

Sari, M. M., \& Umama, H. A. (2019). Patsambu (Tempat Sampah Bambu) Untuk Peningkatan Kualitas Hidup Bersih Dan Sehat Masyarakat Di Desa Talaga, Kecamatan Mancak, Serang. KAIBON ABHINAYA: JURNAL PENGABDIAN MASYARAKAT, 1(2). https://doi.org/10.30656/ka.v1i2.1537

Yunik'ati, Y., Imam, R. M., Hariyadi, F., \& Choirotin, I. (2019). Sadar Pilah Sampah Dengan Konsep 4R (Reduce, Reuse, Recycle, Replace) Di Desa Gedongarum, Kanor, Bojonegoro. JIPEMAS: Jurnal Inovasi Hasil Pengabdian Masyarakat, 2(2).

https://doi.org/10.33474/jipemas.v2i2.112 2 